\title{
Managing Entrepreneurial Employees Who Bring Their Own IT to Work
}

\author{
David Hudson
}

\author{
"So I gave them over to their stubborn hearts") \\ to follow their own devices. \\ Psalm 81:12
}

\begin{abstract}
Why do some employees invest their own time and money to acquire consumer information technology (IT) for use in the workplace as corporate IT? This behaviour occurs even when their firms already possess considerable IT resources. Moreover, IT governance policies typically oppose the use of unsanctioned IT within the firm. IT governance assumes that the only IT assets that are relevant to the firm are those that are owned by the firm. However, employees can create value for the firm by combining their personal IT assets with the firm's IT assets. Creating novel asset combinations is consistent with entrepreneurship but entrepreneurship theory does not address this type of voluntary employee entrepreneurship using personal IT assets. This article proposes a link between the theory of the firm and entrepreneurship theory to explain why employees act entrepreneurially. This link is significant because it advances the notion that employees of established firms can be entrepreneurial when they use their own consumer IT as corporate IT. This link is also significant because it suggests that managing employee entrepreneurship requires tolerance of value creation that is emergent and can occur within a firm.
\end{abstract}

\section{Introduction}

Employees can be observed using their own consumer IT (e.g., smartphones, touchscreen tablets, software, and Internet services), as corporate IT. Individual employees acquire this technology for their own use, including work done for their employer. Employees who use their own personal IT for work challenge fundamental assumptions about how firms choose, implement, and support tools for knowledge work, and these employees can be perceived as either insubordinate or innovative (Bernoff and Schadler, 2010; tinyurl.com/ b2mmxfl). Academic literature on IT governance and entrepreneurship tends to support the view that consumer IT used as corporate IT is a problem. However, it may be that there is significant opportunity arising from this technology trend.

Consumer IT may be used as corporate IT when there is no equivalent corporate IT available (Wang, 2012; tinyurl.com/6xv5052) or in place of available corporate IT (Moschella, 2009; tinyurl.com/av5mg8y). Consider a situation where customer service employees provide sup- port to customers for firm products by relating symptoms of customer issues to solutions using an online decision tree. One customer service employee, who we will call René, was expected, outside normal working hours, to respond to customer support calls by going to the office or returning home to use secure remote access to company systems. René recognized that the information to perform the support function could be transferred to a personal tablet computer and available wherever that employee happened to be. René found a suitable 'app' and created this mobile support tool on his own time. It is clear that employees such as René no longer see IT departments as the only source for workplace IT (Harris et al., 2012: tinyurl.com/aqqtcuo; The Gartner Group, 2011: tinyurl.com/cg6b66n).

The literature emphasizes the security, support, and cost risks to firms arising from employee use of consumer IT as corporate IT (e.g., Ardoin, 2010: tinyurl.com/aa2uu92; Cane, 2011: tinyurl.com/bqq3e49). The risks arise because employees acquire and support such IT outside traditional firm IT departments and processes. The literature on the benefits of consumer IT 


\section{Managing Entrepreneurial Employees Who Bring Their Own IT to Work}

\section{David Hudson}

used as corporate IT is limited and tends to emphasize employee preference but acknowledges that there may also be firm benefits (Bernoff and Schadler, 2010: tinyurl.com/b2mmxfl; Harris et al., 2012: tinyurl.com/aqqtcuo).

The problem addressed by this article is that there is no explanation based on theory for why employees use consumer IT as corporate IT. Furthermore, A theorybased explanation suggests that managing employee use of consumer IT as corporate IT may be about much more than managing the trade-off between employee preferences and IT security. In our example, proprietary information now resides on René's device but René can be more responsive to customers with less personal disruption. How can the firm best manage René's effort to develop a support tool and the violation of company IT policies and practices?

The objectives of this article are to: i) propose that linking the theory of the firm (tinyurl.com/6s8sju) and entrepreneurship theory offers an explanation for employee use of consumer IT as corporate IT and ii) present the implications for managers. This first objective is significant because it argues that employees of established firms can be entrepreneurial and that consumer IT used as corporate IT is an example of such entrepreneurial effort.

This article is organized as follows. First, the consumer IT used as corporate IT phenomenon is briefly described to frame the problem. Second, the link between the theory of the firm and entrepreneurship theory is described as an explanation for employee use of consumer IT as corporate IT. Third, the implications for management practice are presented. Managing employees who use consumer IT as corporate IT is about managing broadly based entrepreneurship and recognizing the need for change in IT governance of the firm.

\section{Consumer IT Used as Corporate IT}

Consumer IT used as corporate IT is a consequence of the fact that, in 2004, the consumer market for IT products became larger than the enterprise market (Ginsburgh and Alvarez, 2009; tinyurl.com/b6lwt6k). In increasing numbers, consumers bring to work the IT that they have personally acquired (Harris et al., 2012; tinyurl.com/aqqtcuo). A survey of information workers in 2009 indicates that over one third bring devices, applications, or services originally acquired for personal use to work without approval from the IT department
(Bernoff and Schadler, 2010; tinyurl.com/b2mmxfl). By 2015, it is estimated that IT assets and services worth the equivalent of 35 percent of the enterprise IT budget will be managed outside the IT department, and this includes a rapidly growing component that is consumer IT used as corporate IT (The Gartner Group, 2011; tinyurl.com/cg6b66n).

Consumer IT used as corporate IT is distinguished from "BYOD" (Bring Your Own Device), and similar labels, to emphasize that the IT of interest includes not only devices but software applications and Internet-based services as well (e.g., Citrix, 2010; tinyurl.com/cxhg6dt). It is also distinguished from "IT consumerization", a term that has been used to describe instances where the consumer IT is acquired by the firm through traditional IT governance processes (e.g., Harris et al., 2012; tinyurl.com/aqqtcuo). Consumer IT used as corporate IT is chiefly distinguished by the fact that an individual employee acquires it and then uses it for work, such as when René decided to use his own tablet with software that he found on the Internet. René asked for nothing from the firm or its IT department to create a portable support tool.

Because of the importance of IT to firms in most industries, there is a body of literature that describes best practices for IT governance. IT governance includes practices encompassing IT strategy, selection, implementation, and operation (Weill and Ross, 2005; tinyurl .com/btkugmt). IT governance assumes that IT is owned by the firm, not the employee, and emphasizes the virtues of top-down IT standardization. In fact, this literature describes situations where employees individually obtain their own IT as "anarchy" (Weill and Ross, 2005).

There is limited academic literature addressing consumer IT used as corporate IT. Bernoff and Schadler (2010; tinyurl.com/b2mmxfl) and Harris, Ives, and Junglas (2012; tinyurl.com/aqqtcuo) both describe the trend as growing and such use by employees as inevitable because of the pervasiveness of the technology in everyday life. Bernoff and Schadler emphasize that encouraging use of consumer IT as corporate IT is a form of empowerment by firms of their employees but offer no theoretical support for their argument. Harris, Ives, and Junglas describe how IT governance might accommodate consumer IT used as corporate IT but, again, offer no theoretical explanation for why firms ought to do so other than to address the need to maximize employee and firm benefits. 


\section{Managing Entrepreneurial Employees Who Bring Their Own IT to Work}

\section{David Hudson}

\section{Governance}

Governance is the formal allocation of decision rights in a firm and arises as a consequence of a rich body of economic theory that explains why firms exist and how they ought to be managed given why they exist (Foss, 2012: tinyurl.com/76h2xzq; Williamson, 1996: tinyurl.com/ ahoqdr8). The theory of the firm argues that firms are collections of contracts for employment, ownership, equity investment, sales, supply, goods, service, warranty, and so on (Coase, 1937: tinyurl.com/796acxx; Foss, 1996: tinyurl.com/7kfsluj). In our customer support example, the firm's ownership of certain IT assets, support obligations to its customers, the 1-800 call centre service, and René's employment would all be contractual relationships. Contracts document all forms of such economic exchange and, therefore, contracts are the essence of a firm (Jensen and Meckling, 1976; tinyurl.com/6uw7flt).

Because it is impossible to capture all possible eventualities in a contract and because people may interpret what contracts do say to their own advantage, contracts must be overseen by managers (Aghion and Holden, 2011: tinyurl.com/85j3bge; Williamson and Winter, 1993: tinyurl.com/7qgdwjr). In the theory of the firm, managers exist to mitigate opportunistic bad behaviour and to ensure that agents deliver as expected and in unforeseen situations (Nee, 2005; tinyurl.com/7waf4y7). Managers do so by using tools such as process, monitoring, incentives, and allocation of decision rights - who can decide what - that are collectively referred to as firm governance (Foss, 2012; tinyurl.com/76h2xzq).

IT governance is one type of firm governance and includes a large body of literature and standards encompassing decision-making for IT strategy, architecture, technology, platforms, applications, investment, and ongoing operations (Weill and Ross, 2005; tinyurl.com/ btkugmt). IT governance builds on a specific assumption that a goal of governance is to minimize shirking by agents, including employees (Jensen and Meckling, 1976; tinyurl.com/6uw7flt) and an implicit assumption that the only assets that are relevant to the firm are those owned by the firm (Penrose, 1959; tinyurl.com/a38orc9). The fact that René owns certain IT is irrelevant to the firm in this traditional view of governance.

\section{Employees as Entrepreneurs}

It is possible that some employees who use consumer IT as corporate IT are playing Angry Birds or watching last night's "Walking Dead" episode and therefore are shirking using assets that are irrelevant to the firm. However, employees do indicate that their own IT provides "better results" when they do their jobs than IT provided by the firm, that they use their own IT "to do my job to the best of my abilities," that "the software and applications I use are integral for accomplishing my job," and so on (Bernoff and Schadler, 2010; tinyurl.com/b2mmxfl). One quarter of the employees in another survey indicated that they often use their own IT to solve a business problem in their jobs for the firm (Harris et al., 2012; tinyurl.com/aqqtcuo).

Shane and Venkataraman (2000; tinyurl.com/bkgee99) provide one of the most widely referenced definitions of entrepreneurship in management journals. They define the field of entrepreneurship as how, by whom, and with what effects opportunities to create future goods and services are discovered, evaluated, and exploited. Where employees use their consumer IT as corporate IT and create value for the firm, possibly in combination with firm assets, then that use would appear to meet the definition of entrepreneurship.

However, entrepreneurship theory emphasizes founders who are motivated by profit and the use of firm assets (Penrose, 1959: tinyurl.com/a38orc9; Shane, 2012: tinyurl.com/aznwf4n). Entrepreneurship theory does not focus on entrepreneurial effort by employees except within formally sanctioned corporate venturing or intrapreneurship initiatives (Amit et al., 1993; tinyurl.com/ax3yya4). Employee use of consumer IT as corporate IT is not led by management. For example, René created his portable customer-support tool without either instruction or approval from a manager.

\section{Linking the Theory of the Firm and Entrepreneurship Theory}

A link between the theory of the firm and entrepreneurship theory is proposed to explain a phenomenon that neither theory can explain on its own: employee use of consumer IT as corporate IT. The link advances that employees who act entrepreneurially combine their own consumer IT with firm IT to create value for their firms and to benefit themselves. Below, three key concepts are used to develop the link between the theory of the firm and entrepreneurship theory.

First, managers in firms exist because contracts are incomplete and agents may shirk (Jensen and Meckling, 1976; tinyurl.com/6uw7flt). However, while the theory of the firm emphasizes that agents, such as employees, may perform below the spirit of their contract even if 


\section{Managing Entrepreneurial Employees Who Bring Their Own IT to Work}

\section{David Hudson}

they meet the strict letter of the contract, it is also possible for agents to do the opposite. An agent may use care, materials, or techniques that exceed what a contract specifies without the principal's knowledge. This is "consummate performance, that is, ... performance within the spirit of the contract" (Hart and Moore, 2008; tinyurl.com/c56xtnb). Employees who acquire IT on their own to perform their jobs better than strictly required or possible with the IT provided by the firm can be said to be performing consummately. René voluntarily created a tool to serve customers that, initially, was not visible to his manager because it was used outside of normal working hours. Creation of a tool was not part of René's job description but addressed a desire to provide superior customer service within a healthy working environment, which is consistent with the spirit of René's employment.

Second, employees may also make investments when they work to the spirit of their contracts. If there is an investment made in expectation of an uncertain return then the effort is not only consummate, it is also entrepreneurial (Shane and Venkataraman, 2000; tinyurl.com/bkgee99). The creation of value from novel combinations of employee IT assets with firm IT assets is entrepreneurial (Foss et al., 2007; tinyurl.com/d77uotf). Employees may invest through the financial cost of their IT. Employees may see benefit to themselves in terms of future advancement in position or salary, and the firm may see benefit through productivity gains or new products and services. Although René already owned the tablet, he acquired software and invested time to make the tablet usable as a remote support tool. Moreover, he later improved the tool to allow co-workers to use the tool on their personal devices.

Third, the investment and return for employee entrepreneurship can be more than monetary given that entrepreneurs calculate the cost-benefit relationship of their actions in more than financial terms (Aldrich, 2005; tinyurl.com/7waf4y7). Employees may invest time through search, learning, and acquisition efforts. The benefits realized by employees may include the choice of workplace, co-workers, or tools (Jensen and Meckling, 1976; tinyurl.com/6uw7flt). Employees using consumer IT as corporate IT may also perceive benefit through their "human capital tied to particular technologies ... with which they are familiar" (Hart and Holmstrom, 2010; tinyurl.com/bver2xy).

This non-monetary employee benefit can be more generally described as emancipation. Where technology change increases uncertainty by threatening the firm's environment (Dosi et al., 2005; tinyurl.com/7waf4y7), then emancipation can be understood as a reaction by individuals who are uncomfortable with leaving the response to change to others (Alvesson and Willmott, 1992; tinyurl.com/cntmnks). Emancipation includes efforts by employees to take control over their environment and satisfies an entrepreneur's "moral obligation to act" rather than being directed towards personal monetary gain (Courpasson et al., 2011; tinyurl.com/a2ajotv). René's actions were initially a response to his desire to respond to customers while minimizing disruption to his own life. Customers likely perceived some improvement in responsiveness while René, and later his coworkers, found that they could perform their jobs with more control over where and when work was done.

Therefore, consummate performance by employees using consumer IT as corporate IT would be demonstrated by use of IT to do more than strictly required to perform assigned tasks. Such effort is entrepreneurial if it requires some investment and creates value for the employee or for the firm from new asset combinations. Investment could be monetary, such as the purchase of a tablet or smartphone for use at work, or it could be non-monetary, such as personal time René spent finding and acquiring the software for his support tool. Benefit to the employee that includes rearranging the employee's environment, such as when, where, with whom, and how work is performed, would be a consistent with emancipation. The firm benefits through improved performance from its employees and possibly from new products or services. The linked theories then explain consumer IT used as corporate IT as an instance of how employees of established firms can be entrepreneurial.

\section{Implications for Managers}

Different approaches to managing employees affect entrepreneurial effort. For example, some research argues for having responsibility for entrepreneurship widely held in established firms rather than centralizing it, if managers wish to increase entrepreneurship: "More innovation will occur if the decision to innovate is dispersed among many diverse individuals than if it is concentrated in the hands of a few" (Bewley, 1989; tinyurl.com/ar2c3y6). Dispersion does not mean isolation, because entrepreneurial effort by one person can stimulate another.

The theory of the firm supports this view. For example, Foss (2012; tinyurl.com/76h2xzq) argues that distributing responsibility for entrepreneurship and tolerating am- 


\section{Managing Entrepreneurial Employees Who Bring Their Own IT to Work}

\section{David Hudson}

biguity may be associated with increased entrepreneurship. The ambiguity here is about who has the right to the benefit from the entrepreneurial effort. Individuals invest effort to take advantage of what they uniquely know where they perceive potential rewards for themselves as well as for the organizations (Jensen and Meckling, 1976; tinyurl.com/6uw7flt). In other words, the potential for private employee benefit must exist to encourage entrepreneurial risk-taking. In creating an IT tool, René invested his own time doing something that was, strictly speaking, not his job because he saw the opportunity and had a sense that he could do it easily. By allowing coworkers to use the tool, he took on a further support responsibility because they could realize similar benefits. Again, IT support was beyond René's job description.

Facilitation of employee entrepreneurship within firms may also include supporting appropriate norms and reward systems (Ireland et al., 2009; tinyurl.com/b6g9r4k). Interestingly, others argue that "resistance activities such as resisting oppression and breaking free from constraints - can actually foster entrepreneurial processes" (Courpasson et al., 2011; tinyurl.com/a2ajotv). It is possible, therefore, that entrepreneurial effort responds to both supportive management acts as well as to certain organizational constraints. Employees react to the opportunity to reshape their environment using IT that they choose themselves, for example, to improve how they perform their jobs. Management at René's firm became aware of the support tool, which by then had been augmented with photographs and other information by the customer support employees to improve the usefulness of the portable support tool. At this point, management recognized that benefits clearly outweighed the IT policy violations and sanctioned the activity.

Therefore, management support for employee entrepreneurship must recognize the potential to exist broadly within an organization and that employees may tend to respond to very locally perceived opportunities where they can realize certain personal benefits. René's customer-support tool had reached a point where it worked on a wide range of devices and was sufficiently easy to use, and so it was productized as a customer selfservice tool and added to the firm's portfolio. The key point is that the firm may also see product, service or business process innovation (Bernoff and Schadler, 2010: tinyurl.com/b2mmxfl; Harris et al., 2012: tinyurl.com/ aqqtcuo). As with any entrepreneurial activity, outcomes are often uncertain and surprising (Baker and Nelson, 2005: tinyurl.com/c6svx2e; Foss, 2012: tinyurl.com/76h2xzq).
Consequently, managers must allow that value creation through employee entrepreneurship such as this may require oversight that is tolerant of both risk and emergence.

Employee use of consumer IT as corporate IT will not always be entrepreneurial and entrepreneurial use will not always necessarily be constructive for the firm. However, managers can distinguish constructive entrepreneurial use and further distinguish where this creates the potential for positive change in the firm or IT governance. While the sourcing and support relationships implied by consumer IT used as corporate IT may conflict with how IT governance has been understood, the value created by entrepreneurial employees may be significant. Restricting employees from using consumer IT as corporate IT may not only impinge on employee preferences, it may deny new value creation in many areas of firm operation. Firms depend on innovation for differentiation and therefore must recognize and encourage constructive entrepreneurship by employees. As a practical contribution, the link suggests that managing consumer IT used as corporate IT is about more than how employee preferences affect IT security and other policies.

The IT that is of value to the firm may now include IT that happens to belong to employees. This IT presents an opportunity to entrepreneurs. Some entrepreneurs may take advantage of this opportunity by starting new firms. However, employee entrepreneurs may use this technology to change the firm from within by discovering novel sources and uses for IT and creating a case for change in IT governance to permit, and even encourage, appropriate use of consumer IT as corporate IT.

\section{Conclusion}

Managing employee entrepreneurship requires tolerance of value creation that is emergent and possibly disruptive. Employees may not see what they are doing as particularly innovative and may even emphasize the personal benefit of their effort. However, outcomes that provide significant benefit to the firm can arise. Such outcomes are only possible if governance practices do not drive employee entrepreneurial effort underground or out of the firm. Managers must allow for and encourage efforts by employees to work to the spirit of their contract in this manner as a source of competitive advantage. 


\section{Managing Entrepreneurial Employees Who Bring Their Own IT to Work}

David Hudson

\section{About the Author}

David Hudson is pursuing doctoral studies and is a lecturer in the MBA program at Carleton University's Sprott School of Business in Ottawa, Canada. His research focus considers entrepreneurial effort by employees and changes arising from consumer technology use in industry. Previously, David was the Vice President for Advanced Research and Technology at a large technology firm and has had an extensive career in technology development and product line management. He received Bachelor's and Master's degrees in Systems Design Engineering from the University of Waterloo.

Citation: Hudson, D. 2012. Managing Entrepreneurial Employees Who Bring Their Own IT to Work. Technology

(cc) BY

Innovation Management Review. December 2012: 6-11. 